\title{
Spironolactone ameliorates PIT1-dependent vascular osteoinduction in klotho-hypomorphic mice
}

\author{
Jakob Voelkl, ${ }^{1}$ Ioana Alesutan,, ${ }^{1}$ Christina B. Leibrock, ${ }^{1}$ Leticia Quintanilla-Martinez, ${ }^{2}$ \\ Volker Kuhn, ${ }^{3}$ Martina Feger, ${ }^{1}$ Sobuj Mia, ${ }^{1}$ Mohamed S.E. Ahmed,1 \\ Kevin P. Rosenblatt, ${ }^{4}$ Makoto Kuro-0, ${ }^{5}$ and Florian Lang ${ }^{1}$ \\ 1Department of Physiology and 2Department of Pathology, University of Tübingen, Tübingen, Germany. ${ }^{3}$ Department of Trauma Surgery,
Medical University Innsbruck, Innsbruck, Austria. ${ }^{4}$ Department of Biochemistry and Molecular Biology and Department of Medicine, \\ University of Texas, Galveston, Texas, USA. ${ }^{5}$ Department of Pathology, University of Texas, Dallas, Texas, USA.
}

\begin{abstract}
Klotho is a potent regulator of 1,25-hydroxyvitamin $\mathrm{D} 3\left[1,25(\mathrm{OH})_{2} \mathrm{D}_{3}\right]$ formation and calcium-phosphate metabolism. Klotho-hypomorphic mice ( $k l / k l$ mice) suffer from severe growth deficits, rapid aging, hyperphosphatemia, hyperaldosteronism, and extensive vascular and soft tissue calcification. Sequelae of klotho deficiency are similar to those of end-stage renal disease. We show here that the mineralocorticoid receptor antagonist spironolactone reduced vascular and soft tissue calcification and increased the life span of $\mathrm{kl} / \mathrm{kl}$ mice, without significant effects on $1,25(\mathrm{OH})_{2} \mathrm{D}_{3}, \mathrm{FGF23}$, calcium, and phosphate plasma concentrations. Spironolactone also reduced the expression of osteoinductive Pit1 and Tnfa mRNA, osteogenic transcription factors, and alkaline phosphatase $(A l p l)$ in calcified tissues of $\mathrm{kl} / \mathrm{kl}$ mice. In human aortic smooth muscle cells (HAoSMCs), aldosterone dose-dependently increased PIT1 mRNA expression, an effect paralleled by increased expression of osteogenic transcription factors and enhanced ALP activity. The effects of aldosterone were reversed by both spironolactone treatment and PIT1 silencing and were mitigated by FGF23 cotreatment in HAoSMCs. In conclusion, aldosterone contributes to vascular and soft tissue calcification, an effect due, at least in part, to stimulation of spironolactone-sensitive, PIT1-dependent osteoinductive signaling.
\end{abstract}

\section{Introduction}

Cardiovascular events are the leading cause of death in patients suffering from chronic kidney disease (CKD), and patients with $\mathrm{CKD}$ are considered among the highest risk group for cardiovascular events independent of traditional risk factors (1). Vascular calcification contributes substantially to the risk for cardiovascular events, and the extent of vascular calcification is a strong predictor of cardiovascular and all-cause mortality $(2,3)$. Vascular calcification is part of the mineral bone disorder (MBD) in CKD (4). Vascular calcification in patients with CKD differs from atherosclerotic calcification and affects the elastic lamellae in the artery (5).

The vascular calcification in CKD is similar to that of klothohypomorphic mice ( $k l / k l$ mice) (6). Klotho participates in the tight regulation of 1,25-hydroxyvitamin D3 [1,25(OH $\left.)_{2} \mathrm{D}_{3}\right]$ formation and renal tubular transport of phosphate and calcium, which in turn determines plasma phosphate and $\mathrm{Ca}^{2+}$ concentration (7). $\mathrm{kl} / \mathrm{kl}$ mice carry a disruption in the promoter sequence of the Klotho gene, leading to severe klotho depletion with extensive soft tissue calcification and eventual early death (8). The tissue calcification is considered to result from excessive $1,25(\mathrm{OH})_{2} \mathrm{D}_{3}$ formation and subsequent hypercalcemia and hyperphosphatemia (9). Increased extracellular phosphate concentration induces vascular calcification (10), and elevated plasma phosphate concentration is recognized as a powerful predictor of mortality (11). In patients with CKD, a strong

Authorship note: Jakob Voelkl and Ioana Alesutan contributed equally to this work. Conflict of interest: The authors have declared that no conflict of interest exists. Citation for this article: J Clin Invest. 2013;123(2):812-822. doi:10.1172/JCI64093. reduction of klotho expression is paralleled by elevated plasma phosphate levels, and klotho is considered a biomarker for kidney function in renal disease (6).

Vascular calcification has previously been considered to be a passive process resulting from oversaturation of plasma with $\mathrm{Ca}^{2+}$ and phosphate, but subsequently it has been reported to involve dedifferentiation and reprogramming of vascular smooth muscle cells into an osteo- and chondrogenic phenotype promoting vascular calcification (12). Thus, vascular calcification is an active process (5). Elevated extracellular phosphate concentrations stimulate the reprogramming of vascular cells to promote vascular calcification (10). Compelling evidence points to an essential role of the type III sodium-dependent phosphate transporter (PIT1, also known as SLC20A1) in phosphate-induced calcification (13), a carrier with an additional putative role in renal tubular phosphate transport (14). The osteoblastic reprogramming could be triggered by Tnf- $\alpha$, inducing a cascade of procalcification signaling (15). Tnf- $\alpha$ requires NF- $\kappa \mathrm{B}$ p 65 and the transcriptional regulator Msx2, which is involved in bone development, to induce expression of the chondrogenic/osteogenic transcription factors osterix and Cbfa1 (also known as Runx2) and vascular calcification (16). Cbfa1 is essential for induction of vascular calcification (17). Tnf- $\alpha$ promotes Msx2 expression and thereby mediates vascular calcification via Wnt signaling (18). Wnt3a and Wnt7a in turn mediate osteogenic differentiation of vascular cells via $\beta$-catenin and activation of alkaline phosphatase (ALP) (19). Wnt signaling, an important effector of $\mathrm{Msx} 2$ induced vascular calcification, is augmented in $\mathrm{kl} / \mathrm{kl}$ mice $(19,20)$. Wnt3a further stimulates ALP activity via p38 MAPK phosphorylation (21). Both, osterix and $\mathrm{Cbfa} 1$ are upregulated 
A
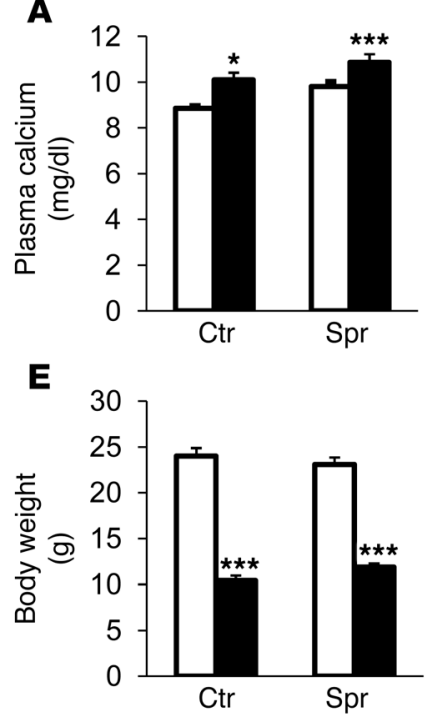

B

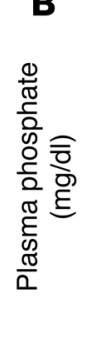

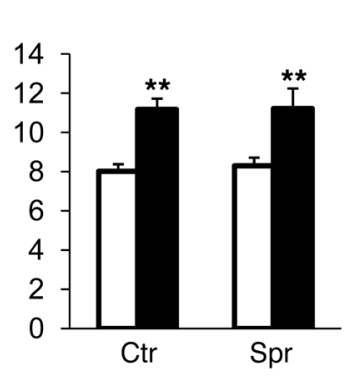

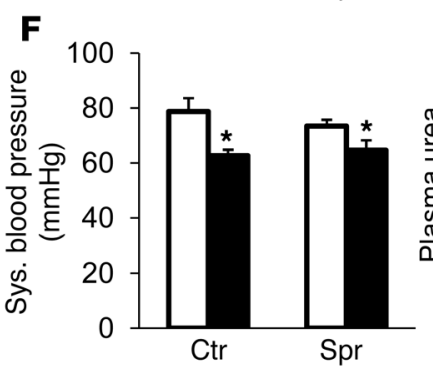

c

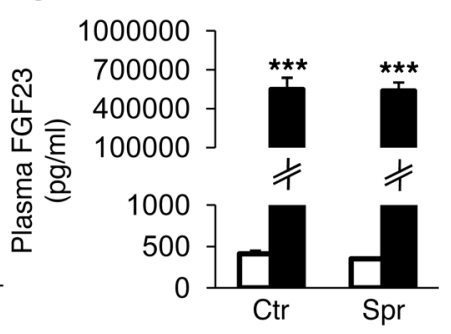

G $60 \quad$ H

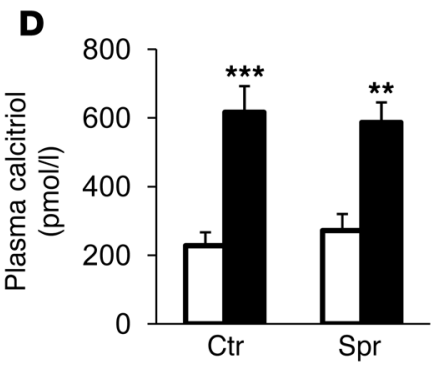

H

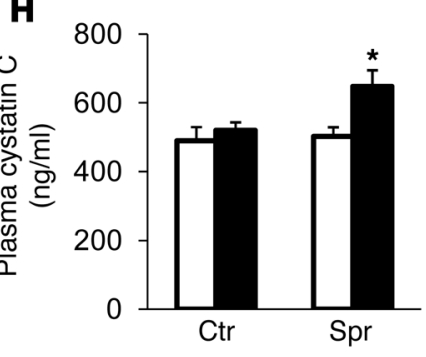

I $\mathrm{k} / \mathrm{k} / \mathrm{survival}$ spironolactone treatment $P=0.008$
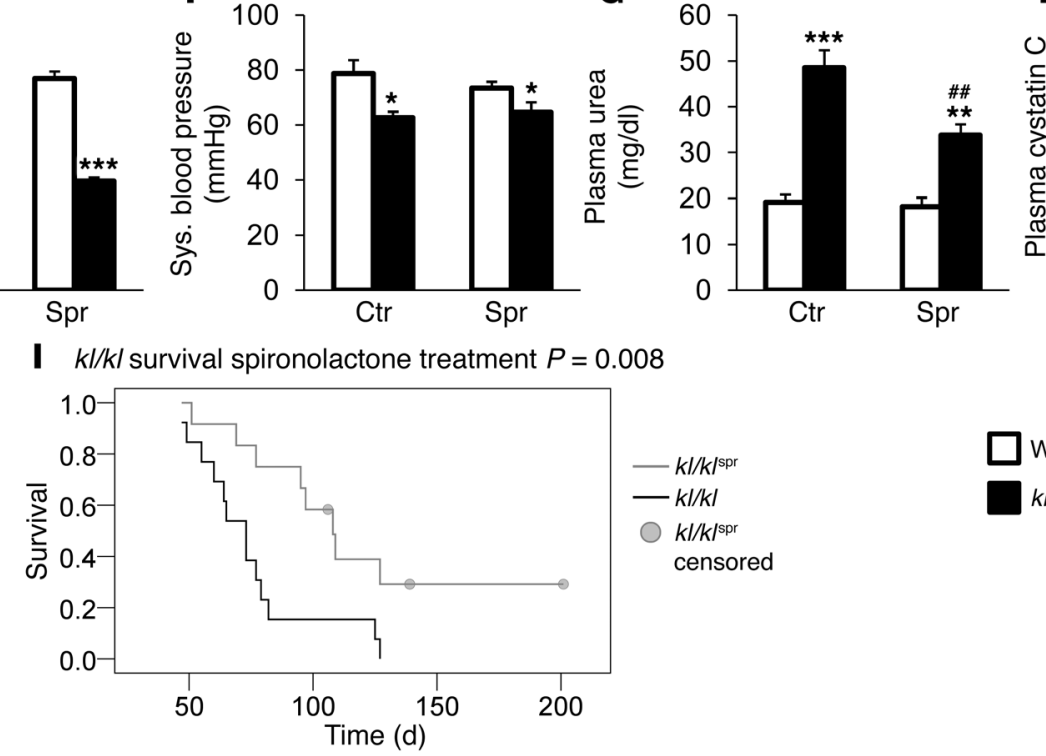


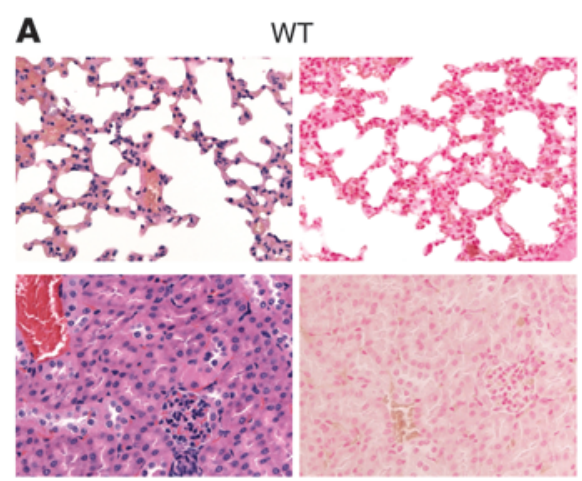

B

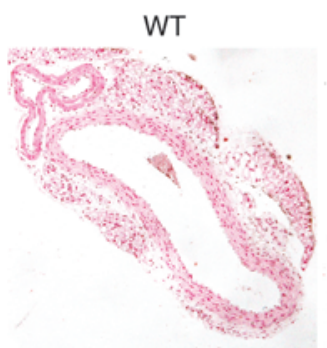

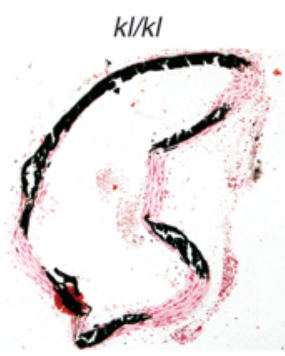
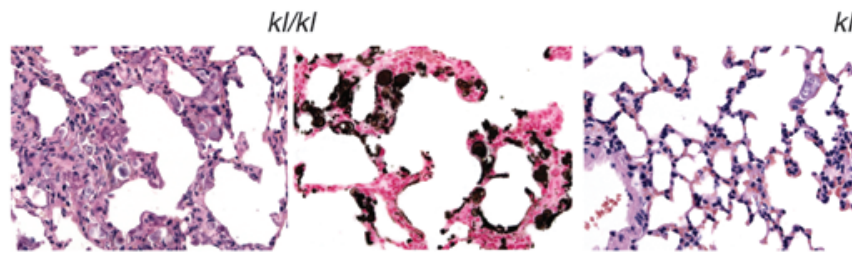

$k l / k / s p r$
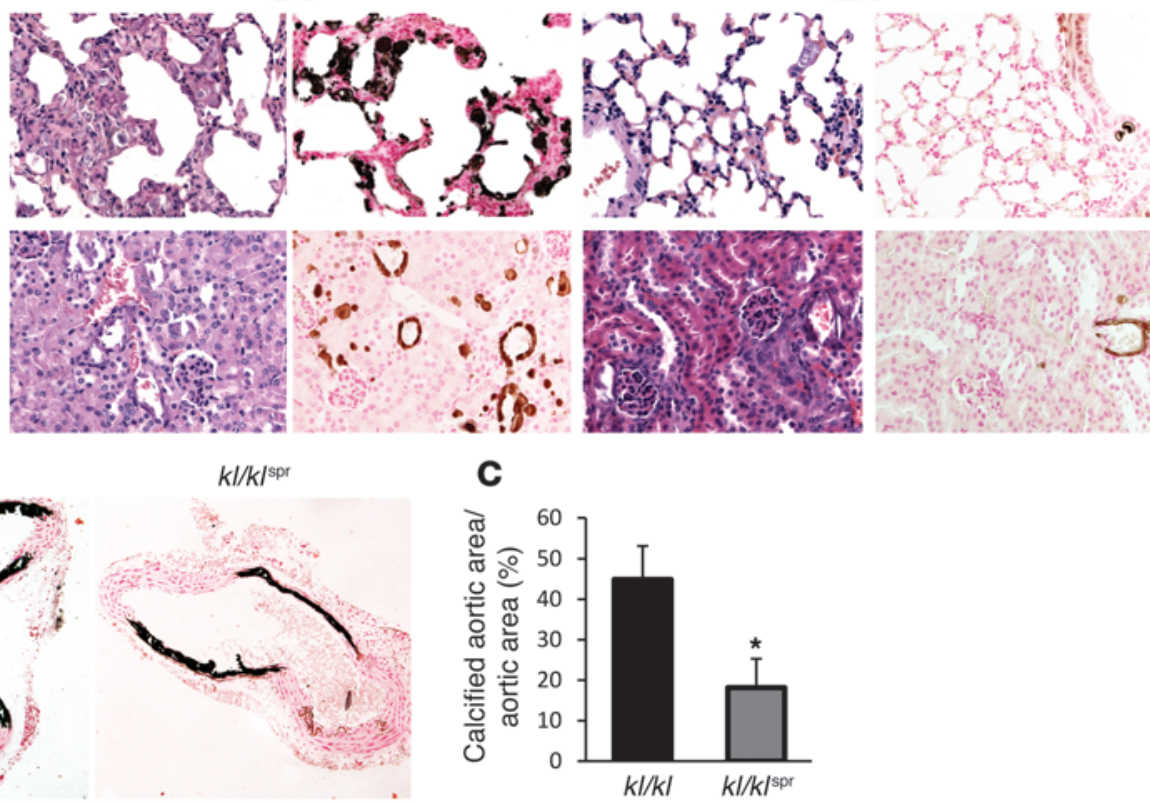

Figure 2

Influence of spironolactone treatment on soft tissue calcification in $\mathrm{kl} / \mathrm{kl}$ mice. (A) H\&E and von Kossa staining of lung (top panels) and kidney (bottom panels) tissue sections (original magnification, $\times 400$ ) from WT mice, $k / / k /$ mice, and $k l / k l$ mice treated with spironolactone. (B) Von Kossa staining of thoracic aorta sections (original magnification, $\times 100$ ) from WT mice, $k / / k l$ mice, and $k l / k /$ mice treated with spironolactone. (C) Arithmetic mean \pm SEM $(n=7)$ of calcified aortic area/total aortic area (\%) in thoracic aorta sections from $\mathrm{kl} / \mathrm{kl}$ mice (black bar) and $\mathrm{kl} / \mathrm{kl}$ mice treated with spironolactone (gray bar). ${ }^{*} P<0.05$, compared with $\mathrm{kl} / \mathrm{kl}$ mice.

observed between spironolactone-treated and untreated $\mathrm{kl} / \mathrm{kl}$ mice. Blood pressure was slightly reduced in the $\mathrm{kl} / \mathrm{kl}$ mice but was not significantly affected by the spironolactone treatment (Figure 1F). The elevated plasma urea nitrogen levels in $\mathrm{kl} / \mathrm{kl}$ mice were reduced by the spironolactone treatment (Figure 1G), but plasma cystatin C levels were elevated by the spironolactone treatment (Figure $1 \mathrm{H}$ ).

Even though spironolactone treatment did not significantly modify hypercalcemia, hyperphosphatemia, or excessive $1,25(\mathrm{OH})_{2} \mathrm{D}_{3}$ and FGF23 plasma concentrations, and even though spironolactone treatment did not appreciably modify the growth deficit of $\mathrm{kl} / \mathrm{kl}$ mice, spironolactone treatment was followed by a slight but statistically significant advantage in survival of $\mathrm{kl} / \mathrm{kl}$ mice (Figure $1 \mathrm{I})$.

Spironolactone reduced tissue calcification in $\mathrm{kl} / \mathrm{kl}$ mice. In search of the underlying mechanisms contributing to or accounting for the effect of spironolactone on the life span of $k l / k l$ mice, animals were subjected to histological evaluation. As illustrated in Figure 2A, extensive soft tissue calcifications were observed in lungs and kidneys of $\mathrm{kl} / \mathrm{kl}$ mice but not of WT mice. The calcifications in $\mathrm{kl} / \mathrm{kl}$ mice were substantially decreased following spironolactone treatment. As von Kossa-positive staining was most abundant in vascular tissue of the organ sections, additional histology was used to analyze calcification in aortic tissue. As a result, calcification in aorta was significantly less pronounced in spironolactone-treated $\mathrm{kl} / \mathrm{kl}$ mice than in control-treated $\mathrm{kl} / \mathrm{kl}$ mice. No calcification was found in WT mice (Figure 2, B and C).

Spironolactone treatment reduced aortic osteoinductive signaling in $\mathrm{kl} / \mathrm{kl}$ mice. As spironolactone treatment reduced calcification in $\mathrm{kl} / \mathrm{kl}$ mice without affecting serum phosphate levels, the effect of spironolactone may have been the result of an inhib- itory effect on aldosterone-dependent active procalcification reprogramming of vascular tissue. As described earlier, $k l / k l$ mice express high levels of Pit 1 , which is considered essential in procalcification reprogramming (6). As shown for aortic tissue (Figure 3), Pit1 transcript levels were significantly higher in $\mathrm{kl} / \mathrm{kl}$ mice than in WT mice. The increased Pit1 transcript levels were significantly decreased following spironolactone treatment of $k l / k l$ mice (Figure 3A). Similarly, the transcript levels of Tnfa, an important initiator of osteoblastic differentiation, were significantly higher in aortic tissue of $\mathrm{kl} / \mathrm{kl}$ mice than in WT mice, a difference again significantly blunted by spironolactone treatment (Figure 3B). Moreover, the mRNA levels of alkaline phosphatase $(A l p l)$ were significantly higher in $\mathrm{kl} / \mathrm{kl}$ mice than in WT mice, a difference again blunted following treatment with spironolactone (Figure 3C). Further experiments addressed Tnf- $\alpha$-dependent signaling. In aortic tissue (Figure 4A), Msx2 mRNA levels were increased in $\mathrm{kl} / \mathrm{kl}$ mice as compared with those in WT mice, a difference significantly blunted by spironolactone treatment. As shown in Figure 4, B and C, the mRNA expression of both the chondrogenic/osteogenic Cbfa1 and the osteogenic osterix (Osx) transcription factors was upregulated in $k l / k l$ mice as compared with WT mice, a difference again blunted by spironolactone treatment. A similar regulation of the osteogenic proteins was found in immunostaining with subsequent confocal microscopy of aortic tissue, showing increased expression of Msx2, Cbfa 1 , and osterix in $\mathrm{kl} / \mathrm{kl}$ mice, which was reduced by spironolactone treatment. In addition, the reduced expression of endothelial nitric oxide synthase in aortas of $k l / k l$ mice was mitigated by spironolactone treatment (Supplemental Figure 1A; supplemental material available online with this 

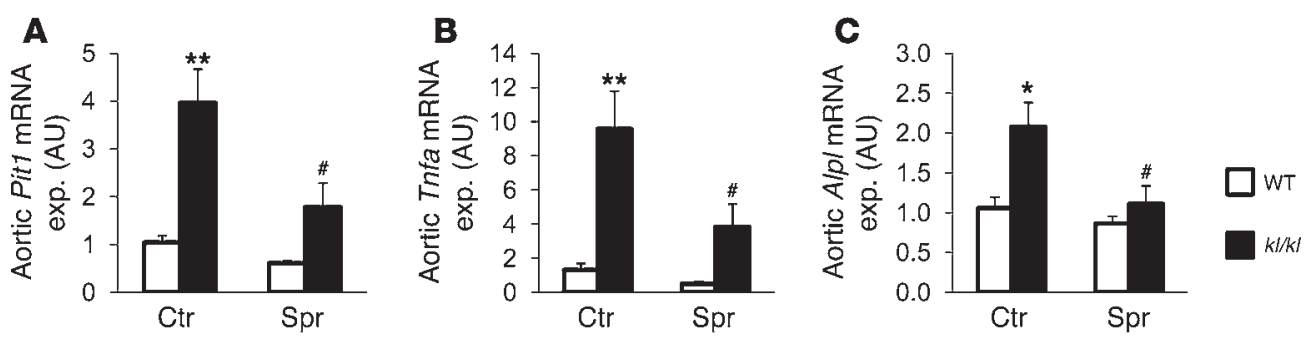

Figure 3

Spironolactone sensitivity of aortic Pit1, Tnfa, and Alpl gene expression. Arithmetic mean \pm SEM ( $n=5-9$; arbitrary units) of aortic (A) Pit1, (B) Tnfa, and (C) Alp/ mRNA levels in WT mice (white bars) and kl/kl mice (black bars), treated with control solution or spironolactone. exp., expression. ${ }^{\sharp} P<0.05$ compared with $\mathrm{kl} / \mathrm{kl}$ mice; ${ }^{*} P<0.05,{ }^{*} P<0.01$ compared with WT control-treated mice.

article; doi:10.1172/JCI64093DS1). This finding was accompanied by a reduction of Pail expression in the $\mathrm{kl} / \mathrm{kl}$ mice following treatment with spironolactone (Supplemental Figure 1B).

Spironolactone reduced osteoinductive signaling in calcified soft tissues of $\mathrm{kl} / \mathrm{klmice}$. In view of the strong calcification in kidney and lung tissue of $\mathrm{kl} / \mathrm{kl}$ mice (Figure 2A), osteoinductive signaling was further analyzed in those tissues. Similar to what has been observed in aortic tissue, renal Tnfa transcript levels were elevated in $\mathrm{kl} / \mathrm{kl}$ mice as compared with those in WT mice, a difference again significantly blunted by spironolactone treatment (Figure 5A). Similarly, renal
$M s x 2, C b f a 1$, and Osx gene transcript levels and Cbfa1 and osterix protein abundance were increased in $k l / k l$ mice as compared with WT mice, a difference again partially prevented by spironolactone treatment (Figure 5, B-E). As shown in Supplemental Figure 2, NF-кB p65, as Tnf- $\alpha$ effector, and Wnt signaling, as effector of Msx2 procalcification signaling, were both upregulated in $\mathrm{kl} / \mathrm{kl}$ mice and reduced by spironolactone treatment.

Similar observations were made in lung tissue. As shown in Supplemental Figure 3A. Pit1 expression was increased in lung tissue from $\mathrm{kl} / \mathrm{kl}$ mice. Again, Pit1 expression was significantly reduced
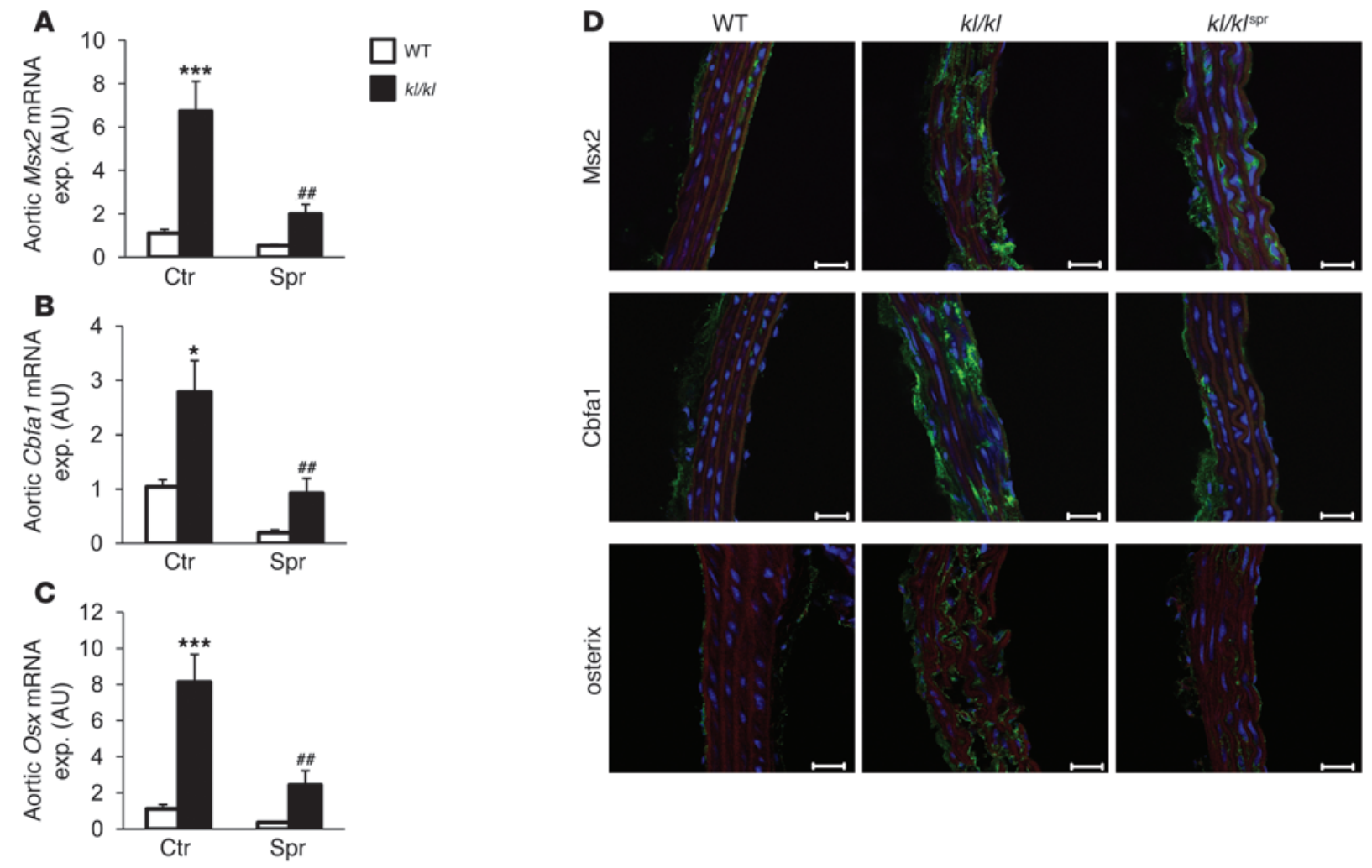

Figure 4

Effect of spironolactone treatment on aortic osteoinductive signaling. Arithmetic mean \pm SEM ( $n=5-9$; arbitrary units) of mRNA levels encoding (A) Msx2, (B) Cbfa1, and (C) Osx in aortic tissue of WT mice (white bars) and kl/kl mice (black bars), treated with control solution (left columns) or spironolactone (right columns). ${ }^{\# \#} P<0.01$, compared with $\mathrm{kl} / \mathrm{kl}$ mice; ${ }^{*} P<0.05,{ }^{* * *} P<0.001$, compared with WT control-treated mice. (D) Immunohistochemical analysis and confocal microscopy (original magnification, $\times 400$ ) of Msx2, Cbfa1, and osterix expression in thoracic aortic tissue of WT mice, $\mathrm{kl} / \mathrm{kl}$ mice, and $\mathrm{kl} / \mathrm{kl}$ mice treated with spironolactone. Osteoblastic marker expression is represented by green labeling, nuclei are labeled in blue, and actin staining is labeled in red. Scale bar: $20 \mu \mathrm{m}$. 
A

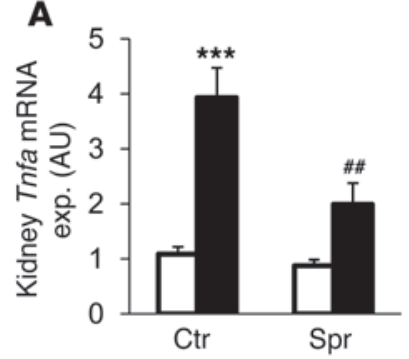

B

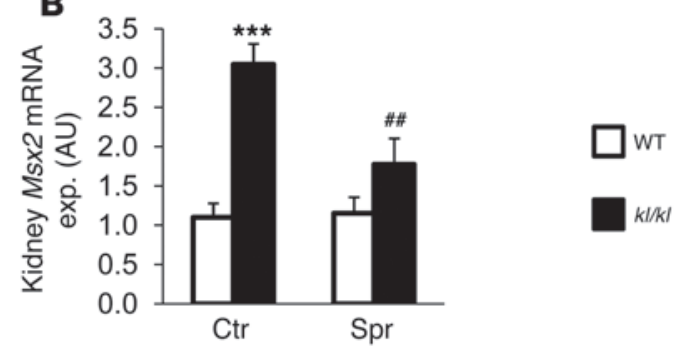

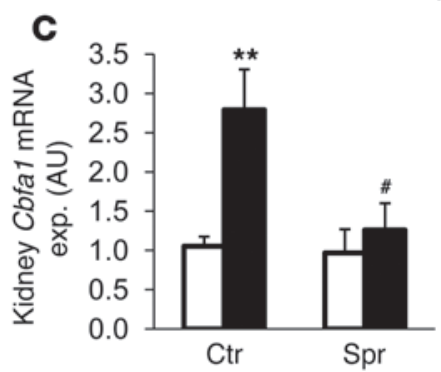

D

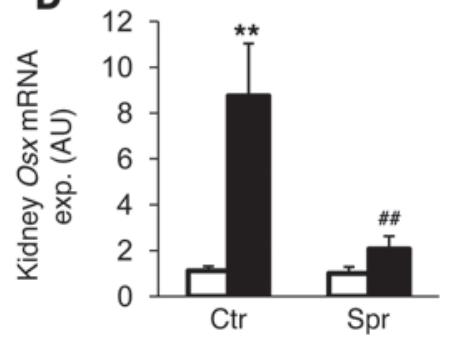

$\mathbf{E}$
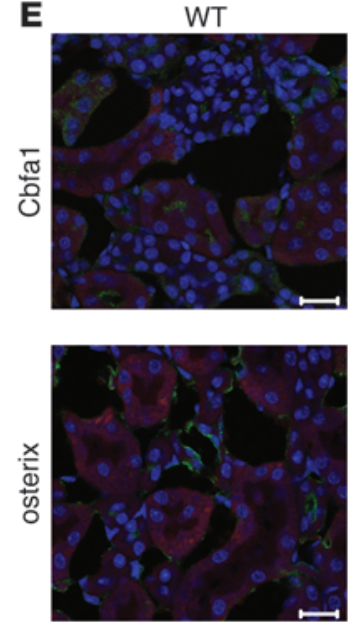
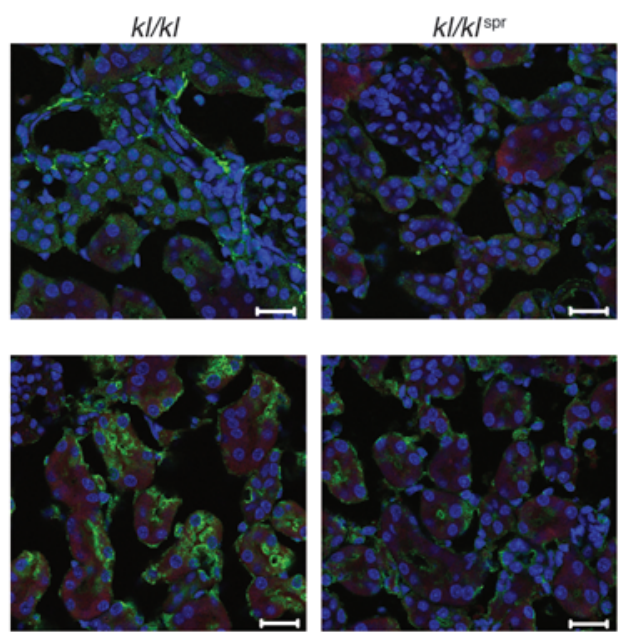

Figure 5

Influence of spironolactone treatment on renal osteoinductive signaling in $\mathrm{kl} / \mathrm{kl}$ mice. Arithmetic mean \pm SEM $(n=7-8$; arbitrary units) of mRNA levels encoding (A) Tnfa, (B) Msx2, (C) Cbfa1, and (D) Osx in renal tissue of WT mice (white bars) and kl/kl mice (black bars), treated with control solution or spironolactone. ${ }^{\#} P<0.05$, ${ }^{\# \#} P<0.01$, compared with $\mathrm{kl} / \mathrm{kl}$ mice; ${ }^{* *} P<0.01$, ${ }^{* * *} P<0.001$, compared with WT control-treated mice. (E) Immunohistochemical analysis and confocal microscopy (original magnification, $\times 400$ ) of Cbfa1 and osterix expression in renal tissue of WT mice, $\mathrm{kl} / \mathrm{kl}$ mice, and $\mathrm{kl} / \mathrm{kl}$ mice treated with spironolactone. Osteoblastic marker expression is represented by green labeling, nuclei are labeled in blue, and actin staining is labeled in red. Scale bar: $20 \mu \mathrm{m}$.

by spironolactone treatment. Furthermore, mRNA expression of Tnfa and Alpl (Supplemental Figure 3, B and C) as well as Msx2, Cbfa1, and Osx (Supplemental Figure 4, A-C) was significantly higher in $\mathrm{kl} / \mathrm{kl}$ mice as compared with WT mice, a difference again significantly blunted by spironolactone treatment. These findings were also reflected by an increased protein abundance of Msx2, $\mathrm{Cbfa} 1$, and osterix in lung tissue of $\mathrm{kl} / \mathrm{kl}$ mice, which was reduced by spironolactone treatment (Supplemental Figure 4D).

Aldosterone enhanced osteoinductive signaling in HAoSMCs via PIT1. In order to further define causal relationships in osteoinductive signaling, primary HAoSMCs were treated for 24 hours with aldosterone and with the MR antagonist spironolactone. To avoid potential effects of endogenous ligands in the medium, the experiments were performed using charcoal-stripped FBS media. In a concentration-dependent manner, aldosterone induced the transcription of type III sodium-dependent phosphate transporter PIT1 (Figure 6). At the concentration of $100 \mathrm{nM}$, aldosterone significantly increased PIT1 transcript levels. At concentrations as low as $0.1 \mathrm{nM}$, aldosterone increased PIT1 mRNA expression (statistically significant in $t$ test as compared with control, $P<0.05$ ). Aldosterone-induced PIT1 mRNA expression was significantly suppressed by cotreatment with $10 \mu \mathrm{M}$ spironolactone. As illustrated in Figure 7 , aldosterone (100 nM) significantly increased the mRNA expression of TNFA, MSX2, CBFA1, and ALPL in HAoSMCs, an effect abrogated by cotreatment with spironolactone $(10 \mu \mathrm{M})$. Moreover, aldosterone treatment significantly enhanced ALP activity in HAoSMCs, an effect abrogated by spironolactone cotreatment (Figure 7E).

Further experiments addressed the role of aldosterone and the protective effects of spironolactone on HAoSMCs at high phosphate concentrations (Figure 8, A and B). Treatment of HAoSMCs with $2 \mathrm{mM} \beta$-glycerophosphate increased PIT1 and CBFA1 mRNA expression. Addition of aldosterone to the high phosphate medium significantly increased the expression of PIT1 and CBFA1 as compared with high phosphate medium alone. Interestingly, spironolactone exerted a profound effect on PIT1 and CBFA1 expression induced by high phosphate medium beyond counteracting the effects of added aldosterone.

Additional experiments addressed the role of FGF23 in aldosterone-induced osteoblastic differentiation. To this end, HAoSMCs were treated with $100 \mathrm{nM}$ aldosterone and/or $5 \mathrm{ng} / \mathrm{ml}$ human FGF23 with or without silencing of klotho (Figure 8, C-F). Treatment of HAoSMCs with FGF23 blunted the effects of aldosterone treatment on PIT1 and CBFA1 mRNA expression. The protective effects of FGF23 were abrogated by silencing of klotho in HAoSMCs. 


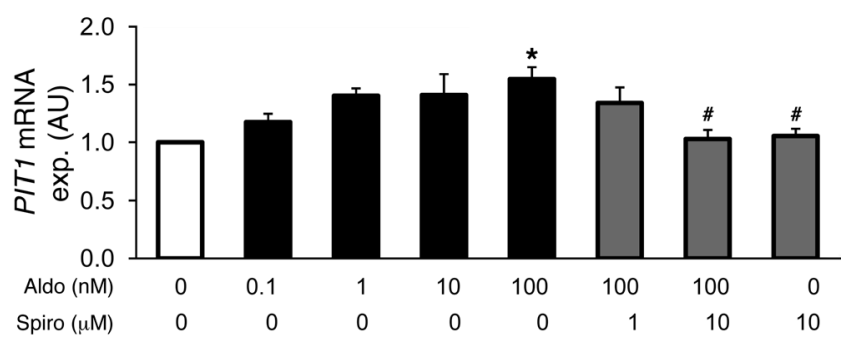

Figure 6

Aldosterone sensitivity of PIT1 gene expression in HAoSMCs. Arithmetic mean \pm SEM ( $n=6$; arbitrary units) of PIT1 mRNA levels in HAoSMCs after 24-hour treatments with vehicle alone (white bar), with aldosterone (Aldo, 1-100 nM, black bars), or with spironolactone (Spiro, 0-10 $\mu \mathrm{M}$, gray bars). ${ }^{*} P<0.05$, compared with HAoSMCs treated with $100 \mathrm{nM}$ aldosterone alone; ${ }^{*} P<0.05$, compared with HAoSMCs treated with vehicle alone.

Additional experiments addressed the role of PIT1 in aldosterone-induced osteoblastic differentiation. To this end, RNA interference was used to suppress endogenous PIT1 mRNA levels in HAoSMCs. To confirm the effects of silencing on HAoSMCs, PIT1 expression levels were examined by quantitative RT-PCR. As shown in Figure 9, PIT1 mRNA levels were significantly reduced in HAoSMCs silenced with PIT1 siRNA but not in HAoSMCs transfected with the negative control siRNA. Treatment with $100 \mathrm{nM}$ aldosterone significantly upregulated the transcript levels of TNFA, MSX2, CBFA1, and ALPL in HAoSMCs pretreated with negative control siRNA. In contrast, TNFA, MSX2, CBFA1, and ALPL mRNA levels were not increased in response to aldosterone in the HAoSMCs silenced with PIT1 siRNA (Figure 9, C-F). These results suggest that PIT1 contributed to or even accounted for induction of osteogenic gene expression in HAoSMCs by aldosterone. Moreover, ALP activity was increased by aldosterone, an effect again abrogated in HAoSMCs silenced with PIT1 siRNA (Figure 9G).

\section{Discussion}

Similar to patients with CKD, $k l / k l$ mice develop severe MBD, with extensive vascular calcification (6). The present observations reveal that vascular calcification of $k l / k l$ mice can be mitigated by spironolactone treatment. According to the present observations, aldosterone stimulates the expression of chondrogenic/osteogenic transcription factors and of ALP in vitro and in vivo. The blockage of aldosterone by the MR receptor antagonist spironolactone mitigates the effects of aldosterone and reduces the procalcification signaling in vitro and in vivo.

Similar to human CKD, the $\mathrm{kl} / \mathrm{kl}$ mouse shows elevated aldosterone levels $(27,28)$. Vascular smooth muscle cells possess the MR receptor, and aldosterone is known to promote vascular calcification (33-35). Aldosterone further increases Tnfa expression (36) and upregulates Bmp2, which does, however, not seem to be required for the procalcifying properties of aldosterone (34). The present observations provide further insight into the spironolactone-sensitive signaling leading to vascular calcification. The results showing aldosterone effects on the HAoSMCs point to a causal role of SLC20A1, which has emerged as a key factor in vascular calcification $(37,38)$. Aldosterone dose-dependently upregulates PIT1 expression and potentiates the effects of phosphate on PIT1 expression. The profound protective effects of spironolactone indicate an intrinsic activation of the MR at high extracellular phosphate concentration. More importantly, silencing of PIT1 completely abrogated all effects of aldosterone on osteoinductive
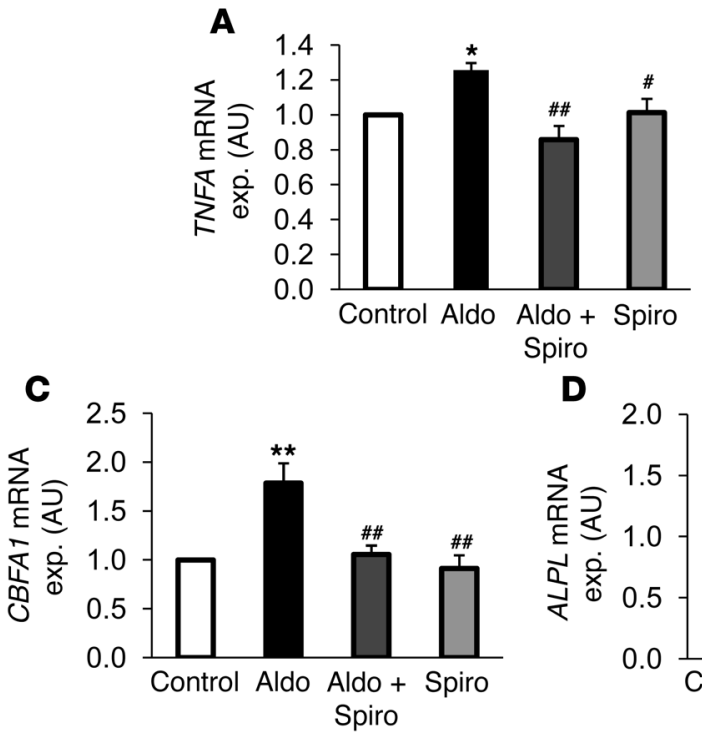

B

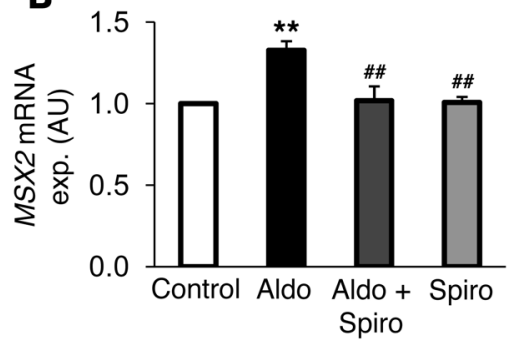

D

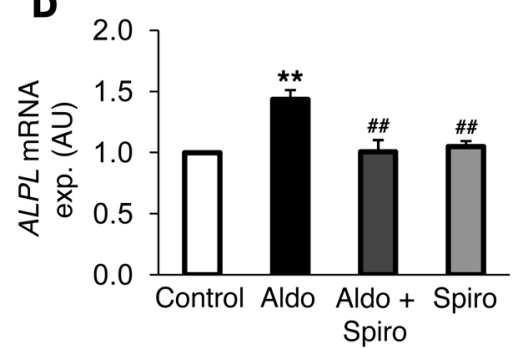

E

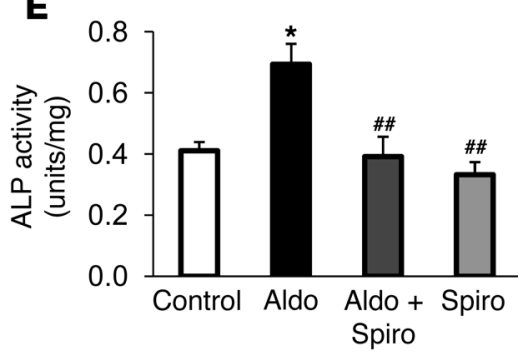

\section{Figure 7}

Influence of aldosterone on TNFA expression and osteoinductive signaling in HAoSMCs. Arithmetic mean \pm SEM $(n=6$; arbitrary units) of mRNA levels encoding (A) TNFA, (B) MSX2, (C) CBFA1, and (D) ALPL in HAoSMCs after 24-hour treatments with vehicle alone (Control, white bars), with $100 \mathrm{nM}$ aldosterone alone (Aldo, black bars), with $100 \mathrm{nM}$ aldosterone and $10 \mu \mathrm{M}$ spironolactone (Aldo+Spiro, dark gray bars), or with $10 \mu \mathrm{M}$ spironolactone alone (Spiro, light gray bars). (E) Arithmetic mean \pm SEM ( $n=4 ; \mathrm{U} / \mathrm{mg}$ protein) of ALP activity of whole cell extracts from HAoSMCs after 7-day treatments with vehicle alone (white bar), with $100 \mathrm{nM}$ aldosterone alone (black bar), with $100 \mathrm{nM}$ aldosterone and $10 \mu \mathrm{M}$ spironolactone (dark gray bar), or with $10 \mu \mathrm{M}$ spironolactone alone (light gray bar). ${ }^{P} P<0.05, \# P<0.01$, compared with HAoSMCs treated with $100 \mathrm{nM}$ aldosterone alone; ${ }^{\star} P<0.05,{ }^{* \star} P<0.01$, compared with HAoSMCs treated with vehicle alone. 
A

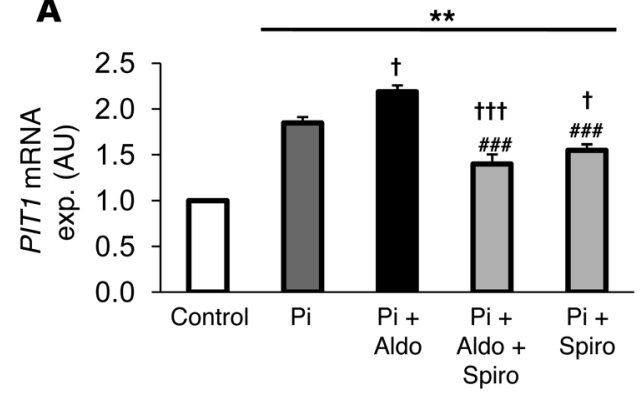

C

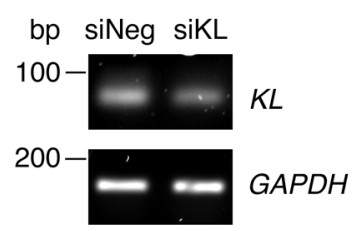

E

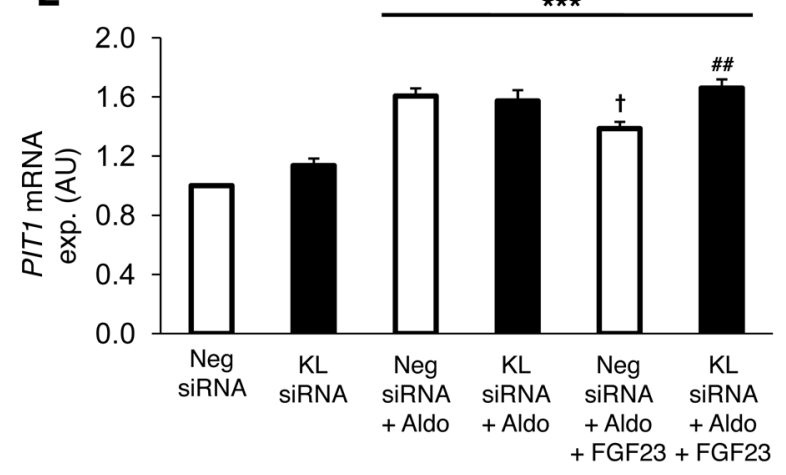

B

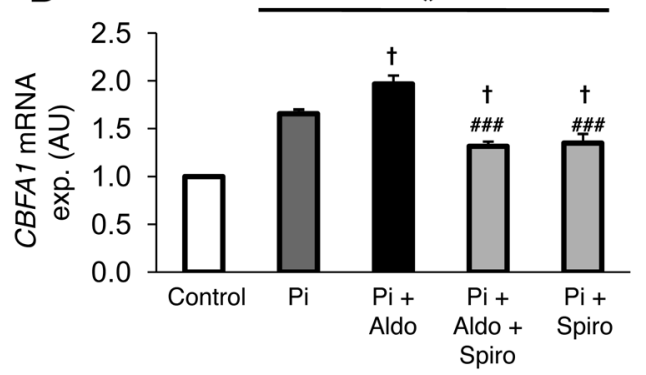

D

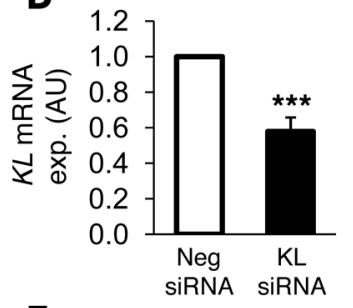

$\mathbf{F}$

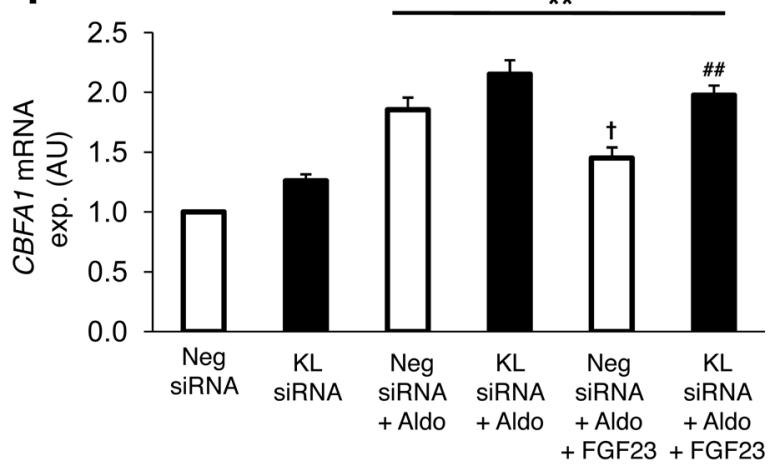

Figure 8

Effects of aldosterone/spironolactone in high phosphate conditions and of FGF23 during aldosterone treatment on PIT1 and CBFA1 expression in HAoSMCs. Arithmetic mean \pm SEM ( $n=6-9$; arbitrary units) of mRNA levels encoding (A) PIT1 and (B) CBFA1 in HAoSMCs after 24-hour treatments with vehicle alone (Control, white bars), with $2 \mathrm{mM} \beta$-glycerophosphate ( $\mathrm{Pi}$, dark gray bars), or with cotreatment with $100 \mathrm{nM}$ aldosterone ( $\mathrm{Pi}+\mathrm{Aldo}$, black bars), $100 \mathrm{nM}$ aldosterone/10 $\mu \mathrm{M}$ spironolactone (Pi+Aldo+Spiro, light gray bars), or $10 \mu \mathrm{M}$ spironolactone (Pi+Spiro, light gray bars). (C) Representative original bands of $K L O T H O(K L)$ and calibrator/control GAPDH mRNA expression. (D) Arithmetic mean \pm SEM $(n=6$; arbitrary units) of $K L$ mRNA levels in HAoSMCs after 48-hour silencing with $10 \mathrm{nM}$ of negative control siRNA (Neg. siRNA, white bar) or with $10 \mathrm{nM}$ klotho siRNA (KL siRNA, black bar). Arithmetic mean \pm SEM $(n=8-9$; arbitrary units) of mRNA levels encoding (E) PIT1 and (F) CBFA1 in HAoSMCs after 48-hour silencing with $10 \mathrm{nM}$ negative control siRNA (white bars) or with $10 \mathrm{nM}$ klotho siRNA (black bars), without or with $100 \mathrm{nM}$ aldosterone and $5 \mathrm{ng} / \mathrm{ml} \mathrm{FGF23} \mathrm{(Aldo+FGF23)} \mathrm{treatment} \mathrm{for} 24$ hours. ${ }^{*} P<0.05$, ${ }^{* *} P<0.01$, ${ }^{* \star *} P<0.001$, compared with control-treated HAoSMCs. ${ }^{\dagger} P<0.05,{ }^{\dagger \dagger} P<0.001$, compared with HAoSMCs treated with $2 \mathrm{mM} \beta$-glycerophosphate or aldosterone alone. \# $P<0.01$, \#\#\# $P<0.001$, compared with HAoSMCs treated with $2 \mathrm{mM} \beta$-glycerophosphate and $100 \mathrm{nM}$ aldosterone or HAoSMCs silenced with negative control siRNA and treated with $100 \mathrm{nM}$ aldosterone and $5 \mathrm{ng} / \mathrm{ml}$ FGF23.

signaling. The exact mechanism of how PIT1 mediates vascular calcification is still elusive (37). PIT1 may not be primarily effective by mediating cellular phosphate uptake (39). PIT1 mainly localizes to the sarcoplasmic reticulum, and its cell surface expression is not the key to vascular calcification (39). As reported earlier $(38,39)$, PIT1 expression is insensitive to TNF- $\alpha$. We show that conversely TNFA expression is sensitive to PIT1, as PIT1 silencing decreases TNFA expression induced by aldosterone, indicating that in vascular smooth muscle cells PIT1 may be upstream instead of downstream of TNFA expression. Ample evidence underscores the importance of TNF- $\alpha$ and the TNF- $\alpha$-sensitive signaling leading to initiation of vascular smooth muscle cell osteoblastic differentiation (5). According to the present observations, aldosterone increases expression of PIT1, which is in turn required for expres- sion of TNFA and chondrogenic/osteogenic transcription factors, MSX2 and CBFA1, and ALPL as well as ALP activity. It is tempting to speculate that PIT1 transcription is regulated directly by the aldosterone-MR complex, as the promoter sequence of the PIT1 gene contains putative MR response elements MRE/GRE.

Nevertheless, other factors beside aldosterone regulate PIT1 $(38,39)$. The expression of PIT1 is decreased in a klotho-overexpressing mouse line, pointing to an additional inhibitory effect of klotho on PIT1 expression (6). Klotho is expressed in vascular smooth muscle cells and is required for the vasculoprotective effects of FGF23 signaling (25). In accordance, FGF23 mitigates the effects of aldosterone on PIT1 expression and subsequent chondrogenic/ osteogenic signaling, as determined by CBFA1 expression in HAoSMCs. The in vitro findings of PIT1 mediating the effects of 
A

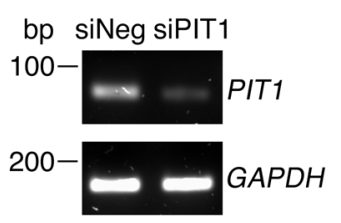

B
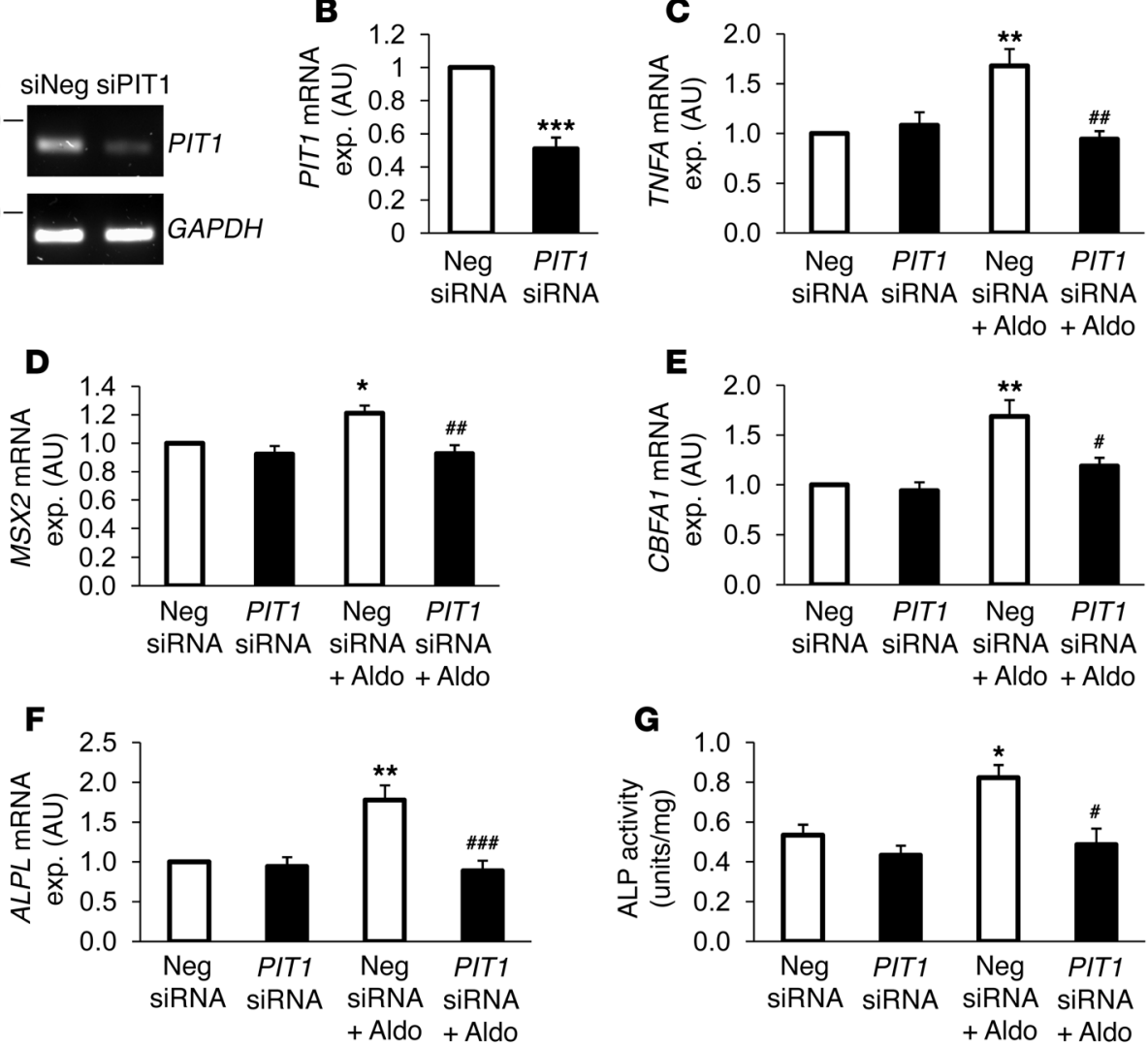

E

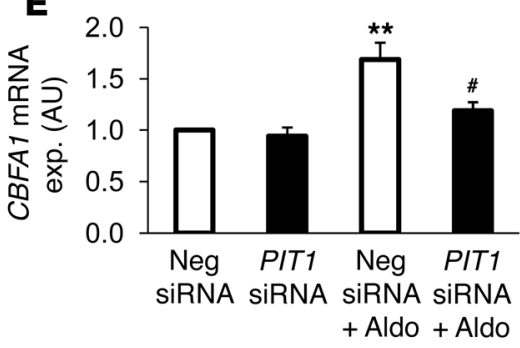

G

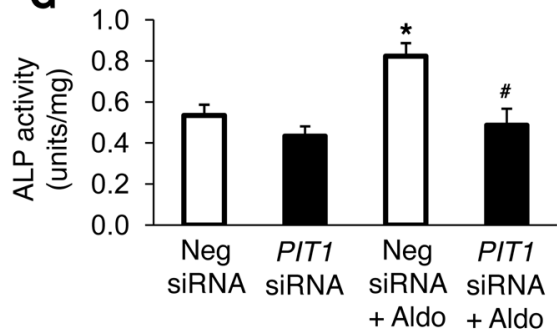

Figure 9

PIT1 dependence of aldosterone-induced TNFA expression and osteoinductive signaling in HAoSMCs. (A) Representative original bands of PIT1 and calibrator/control GAPDH mRNA expression in HAoSMCs after 48-hour silencing with $10 \mathrm{nM}$ of negative control siRNA or with $10 \mathrm{nM}$ PIT1 siRNA. (B) Arithmetic mean \pm SEM ( $n=6$; arbitrary units) of PIT1 mRNA levels in HAoSMCs after 48-hour silencing with $10 \mathrm{nM}$ of negative control siRNA (white bar) or with $10 \mathrm{nM}$ PIT1 siRNA (black bar). Arithmetic mean \pm SEM ( $n=6$; arbitrary units) of mRNA levels encoding (C) TNFA, (D) MSX2, (E) CBFA1, and (F) ALPL in HAoSMCs after 48-hour silencing with $10 \mathrm{nM}$ of negative control siRNA (white bars) or with $10 \mathrm{nM}$ PIT1 siRNA (black bars), without or with treatment for 24 hours with $100 \mathrm{nM}$ aldosterone. (G) Arithmetic mean \pm SEM ( $n=4 ; \mathrm{U} / \mathrm{mg}$ protein) of ALP activity of whole cell extracts from HAoSMCs after 7-day silencing with $10 \mathrm{nM}$ of negative control siRNA (white bars) or with $10 \mathrm{nM}$ PIT1 siRNA (black bars), without or with treatment with $100 \mathrm{nM}$ aldosterone. ${ }^{\#} P<0.05$, ${ }^{\#} P<0.01$, \#\#\#P<0.001, compared with HAoSMCs silenced with negative control siRNA and treated with $100 \mathrm{nM}$ aldosterone; ${ }^{*} P<0.05$, ${ }^{* *} P<0.01$, ${ }^{* * *} P<0.001$, compared with HAoSMCs silenced with negative control siRNA.

aldosterone do not rule out other effects of spironolactone treatment. Endothelial cells are involved in the induction of vascular calcification, and aldosterone has detrimental effects on the endothelium and the vasculature $(40,41)$. Aldosterone downregulates eNos, an effect reversed by spironolactone (30). Nitric oxide interferes with vascular calcification by regulating Pai1 (42). Enhanced Pail expression has similarly been observed in the $\mathrm{kl} / \mathrm{kl}$ mice (43).

However, the phenotype of the $\mathrm{kl} / \mathrm{kl}$ mice and the FGF23 knockout mice results from excessive formation of $1,25(\mathrm{OH})_{2} \mathrm{D}_{3}$ and subsequent hyperphosphatemia, as it is reversed by vitamin Ddeficient or low phosphate diet $(27,44-46)$. In CKD, $1,25(\mathrm{OH})_{2} \mathrm{D}_{3}$ formation is reduced and the vascular calcification results from hyperphosphatemia due to impaired renal phosphate elimination, although the use of phosphate binders was recently questioned $(4,10,11,47)$. Paradoxically, $1,25(\mathrm{OH})_{2} \mathrm{D}_{3}$ agonists were shown to actually decrease vascular calcification and exert beneficial effects in vascular tissues (48). Thus, $1,25(\mathrm{OH})_{2} \mathrm{D}_{3}$ may play a dual role in tissue calcification. Although $1,25(\mathrm{OH})_{2} \mathrm{D}_{3}$ increases plasma Ca ${ }^{2+}$ and phosphate concentrations, it suppresses NF- $\kappa \mathrm{B}$ and TNF- $\alpha$ (49), which in turn are involved in the stimulation of vascular calcification (50-52). This could also be influenced by the induction of klotho expression by $1,25(\mathrm{OH})_{2} \mathrm{D}_{3}$, which enables FGF23 binding and subsequent protective signaling (25). FGF23 exerts profound protective effects on the vasculature in high phosphate conditions; however, this effect requires klotho as a cofactor. In patients with CKD, klotho expression could be stimulated by $1,25(\mathrm{OH})_{2} \mathrm{D}_{3}$, an effect blunted or lacking in the $\mathrm{kl} / \mathrm{kl}$ mice. The extremely high serum levels of $\mathrm{FGF} 23$ in $k l / k l$ mice are therefore most likely unable to exert vasculoprotective effects, a condition similar to human patients with CKD.

There may be a crosstalk between klotho and the renin-angiotensin-aldosterone system, as vascular cells express Cyp11b2 and are capable of producing aldosterone (53-57). Aldosterone may further promote the osteochondrogenic remodeling of vascular smooth muscle cells by downregulating klotho and thereby mediating FGF23 resistance $(6,57)$, nonetheless, following aldosterone treatment, HAoSMCs still respond to FGF23 treatment, which counteracts the effects of aldosterone.

The importance of other factors beside aldosterone involved in vascular calcification is reflected by the finding that spironolactone treatment could not abrogate, but only reduce the calcification-prone phenotype of $k l / k l$ mice, despite profound protective effects in vitro. The study is further limited by other possible effects of spironolactone in vivo. Although in vitro experiments with aldosterone suggest an important role of MR activation in vascular calcification, the beneficial effects of spironolactone in vivo may only partially be due to MR inhibition. Spironolactone inhibits also other receptors, most notably the androgen receptor, and prevents bone loss in hyperandrogenic women, whereas eplerenone is much more selective for the MR receptor and has fewer antiandrogenic side effects $(58,59)$. The androgen receptor is similarly associated with vascular calcification, although its exact role in vascular calcification is still incompletely understood $(60,61)$. Spironolactone treatment further decreased plasma urea nitrogen levels but increased plasma cystatin C levels. Despite the observed effects of spironolactone on 
osteoinductive signaling, the effects of spironolactone treatment on survival were only moderate. Thus, additional mechanisms compromise renal function and limit the life span of $\mathrm{kl} / \mathrm{kl}$ mice.

MBD with vascular calcification is a determinant of the mortality in CKD $(2,3)$. Patients with CKD also suffer from severe hyperphosphatemia, with soft tissue calcifications and arteriosclerosis, resulting in dramatically increased cardiovascular mortality, the most common death of dialysis patients (31). The expression of klotho is strongly reduced in these patients and a sensitive marker of CKD (6). Along those lines, klotho substitution significantly improved the outcome in a CKD model (62). Patients with CKD and $\mathrm{kl} / \mathrm{kl}$ mice share the phosphate overloading and klotho deficiency with resistance to FGF23, which then exerts detrimental effects on the vasculature $(7,63)$. The $k l / k l$ mouse is therefore an established animal model mimicking the pathophysiology of CKD and MBD. The extensive vascular and soft tissue calcification paralleled by induction of a procalcification programming in $\mathrm{kl} / \mathrm{kl}$ mice mimics excessive calcifications in patients with CKD with similar osteoinductive signaling $(22,64)$.

In view of the present observations, aldosterone blockage by spironolactone may reduce vascular calcification and may be considered a therapeutic option in patients with CKD. Spironolactone treatment bears the risk of hyperkalemia but is otherwise well tolerated in patients with early to moderate CKD (65). Thus, even in patients with CKD, the benefits may outweigh the risks of spironolactone treatment.

\section{Methods}

Further information can be found in Supplemental Methods.

Animal experiments. The origin of the mice, breeding, and genotyping were described previously (8). As klotho-deficient mice show severe calcifications at 3 weeks of age $(66,67)$, life-long treatment with spironolactone was maintained in this study. The klotho WT (WT) and $k l / k l$ mice had access to vehicle drinking water without or with addition of $80 \mathrm{mg} / \mathrm{l}$ spironolactone (Sigma-Aldrich) and rodent chow ad libitum $(68,69)$. Blood was collected by retroorbital puncture, and the plasma concentrations of blood urea nitrogen, phosphate, and $\mathrm{Ca}^{2+}$ were measured by a photometric method (FUJI FDC 3500i). An ELISA Kit was used to determine plasma concentrations of $1,25(\mathrm{OH})_{2} \mathrm{D}_{3}$ (Immunodiagnostic Systems), FGF23 (Immutopics), or cystatin C (Biovendor) according to manufacturer's instructions. Blood pressure measurements were performed by left ventricular apical stab technique under isoflurane anesthesia with a pressure transducer (World Precision Instruments). Mice were then sacrificed, and aortic, lung, and kidney tissues were collected for further experiments at approximately 8 to 9 weeks of age.

Cell culture of HAoSMCs. Primary HAoSMCs $(70,71)$ (provided by Dorothea Siegel-Axel, Medical Clinic IV, Department of Endocrinology, Diabetology, Angiology, Nephrology and Clinical Chemistry, University of Tübingen) were routinely cultured in Waymouth's MB 752/1 medium and Ham's F-12 nutrient mixture (1:1, Gibco, Life Technologies) supplemented with $10 \%$ FBS (Gibco, Life Technologies) and $100 \mathrm{U} / \mathrm{ml}$ penicillin and $100 \mu \mathrm{g} / \mathrm{ml}$ streptomycin (Gibco, Life Technologies). HAoSMCs were grown to confluency and used in all experiments from passages 4 to 10 . The media was changed to $10 \%$ charcoal-stripped FBS media (Gibco, Life Technologies) 24 hours prior to each experiment to reduce the effects of endogenous ligands. Unless indicated otherwise, cells were treated for 24 hours with aldosterone and/or spironolactone (Sigma-Aldrich) dissolved in DMSO with $2 \mathrm{mM} \beta$-glycerophosphate (Sigma-Aldrich) or with $5 \mathrm{ng} / \mathrm{ml}$ of human FGF23 (R\&D Systems). Equal amounts of vehicle were used as a control.
For silencing of PIT1 and KLOTHO, HAoSMCs were cultured on 6-well plates $\left(2 \times 10^{5}\right.$ cells per well). The cells were subsequently transfected with $10 \mathrm{nM}$ validated PIT1 siRNA (ID no. s13087, Ambion, Life Technologies) with $10 \mathrm{nM}$ KLOTHO siRNA (ID no. s225119, Ambion, Life Technologies) or with $10 \mathrm{nM}$ negative control siRNA (ID no. 4390843, Ambion, Life Technologies) using siPORT amine transfection agent (Ambion, Life Technologies) according to the manufacturer's protocol. The cells were used 48 hours after transfection. The efficiency of silencing was verified by quantitative RT-PCR.

ALP activity assay. HAoSMCs were cultured on 24 -well plates $\left(4 \times 10^{4}\right.$ cells per well) in $10 \%$ charcoal-stripped FBS media. Where indicated, 1 day after seeding, cells were silenced using $10 \mathrm{nM}$ PIT1 siRNA or $10 \mathrm{nM}$ negative control siRNA, as described previously. HAoSMCs were treated for 7 days with vehicle, aldosterone, and/or spironolactone at the concentrations indicated in the figure legends. Fresh media with agents were added every 2 to 3 days. For determination of cellular ALP activity, cells were washed 3 times with PBS and assayed for ALP activity using the ALP Colorimetric Assay Kit (Abcam) according to the manufacturer's protocol. ALP activity was normalized to total protein concentration, as assessed by the Bradford assay (Bio-Rad Laboratories).

Quantitative RT-PCR. Quantitative RT-PCR was performed as described previously (72). Briefly, after sacrificing the animals, tissues were immediately snap frozen in liquid nitrogen. Total RNA was isolated from mouse tissues by using Trifast Reagent (Peqlab) according to the manufacturer's instructions. HAoSMCs were washed with PBS, and total RNA was isolated using Trifast Reagent (Peqlab) according to the manufacturer's instructions. Reverse transcription of $2 \mu \mathrm{g}$ RNA was performed using oligo(dT) ${ }_{12-18}$ primers (Invitrogen) and SuperScript III Reverse Transcriptase (Invitrogen). cDNA samples were treated with RNaseH (Invitrogen). Quantitative realtime PCR was performed with the iCycler iQ Real-Time PCR Detection System (Bio-Rad Laboratories) and iQ Sybr Green Supermix (Bio-Rad Laboratories) according to the manufacturer's instructions. Further information about primer sequences can be found in the Supplemental Methods. The specificity of the PCR products was confirmed by analysis of the melting curves and in addition by agarose gel electrophoresis. All PCRs were performed in duplicate, and mRNA fold changes were calculated by the $2^{-\Delta \Delta \mathrm{Ct}}$ method using GAPDH as internal reference.

Histology, immunohistochemistry, and confocal microscopy. For histological evaluation, thoracic aortic tissue and lung and kidney tissues from $\mathrm{kl} / \mathrm{kl}$ and WT mice, without or with treatment with spironolactone, were fixed with $4 \%$ paraformaldehyde, embedded in paraffin, cut in 2- to 3- $\mu \mathrm{m} \mathrm{sec-}$ tions, and stained with $\mathrm{H} \& \mathrm{E}$ and von Kossa (73). For quantification, 2 random von Kossa-stained sections from the thoracic aortic tissues were digitized. The surface of the aorta was manually defined as the region of interest, and the surface affected by calcification was manually measured with Adobe Photoshop software (Adobe). The calcified area was calculated as calcified aortic surface/total aortic surface (pixels/pixels).

For immunohistochemistry, paraformaldehyde-fixed thoracic aortic tissue and lung and kidney tissue were cryoprotected in 30\% sucrose, frozen in mounting medium (Tissue-Tek, Sakura Finetek), and sectioned at a thickness of $8 \mu \mathrm{m}$ on coated slides. To reduce nonspecific background staining, slides were incubated with $5 \%$ normal goat serum or with $5 \%$ BSA in PBS/ 0.1\% TritonX for 1 hour at room temperature. Sections were incubated overnight at $4{ }^{\circ} \mathrm{C}$ with the following primary antibodies: rabbit polyclonal anti-Sp7/osterix (diluted 1:75, Abcam), rabbit polyclonal antiCbfa1 (diluted 1:50, Santa Cruz Biotechnology Inc.), or goat polyclonal anti-Msx2 (diluted 1:50, Santa Cruz Biotechnology Inc.). Binding of primary antibodies was visualized using goat anti-rabbit Alexa Fluor 488-conjugated antibody (diluted 1:1,000, Invitrogen) or donkey anti-goat Alexa Fluor 488-conjugated antibody (diluted 1:1,000, Invitrogen) incubated 
for 1 hour at room temperature. Nuclei were stained using DRAQ-5 dye (diluted 1:1,000, Biostatus) and actin using Rhodamine Phalloidin (diluted 1:100, Invitrogen). The slides were mounted with Prolong Gold antifade reagent (Invitrogen). Images were collected with a confocal laser-scanning microscope (LSM 510, Carl Zeiss MicroImaging GmbH) using a water immersion A-Plan $\times 40 / 1.2 \mathrm{~W}$ DICIII. Confocal images are representative for 3 mice per group. Negative controls were carried out simultaneously with all experiments by omitting incubation with primary antibodies.

Statistics. Data are provided as mean \pm SEM; $n$ represents the number of independent experiments. All data were tested for significance using ANOVA following post-hoc analysis with SPSS software or unpaired, 2 -tailed $t$ test where indicated. Four groups were compared: WT mice treated either with spironolactone or with control solution and $\mathrm{kl} / \mathrm{kl}$ mice treated either with spironolactone or with control solution. Two random sections of aortic tissue from untreated and treated $\mathrm{kl} / \mathrm{kl}$ mice were quantified for von Kossa-positive staining. Survival outcome was investigated by Kaplan-Meier plot and tested with log-rank test statistics. In all tests, $P$ values of less than 0.05 were considered statistically significant.

Study approval. All animal experiments were conducted according to the guidelines of the American Physiological Society as well as the German law for the welfare of animals and were approved by the respective authority (Regierungspräsidium Tübingen, Germany). Human aortas were obtained from organ donors after obtaining informed consent (approved by the "Clinical Ethics Committee at the University Hospital Tübingen," Tübingen, Germany).

\section{Acknowledgments}

The authors gratefully acknowledge the outstanding technical assistance of Klaudia Kloß, Dennis Thiele, Elfriede Faber, and Julia Spilcke-Liss and the meticulous preparation of the manuscript by Tanja Loch, Sari Ruebe, and Lejla Subasic. This study was supported by the Deutsche Forschungsgemeinschaft.

Received for publication April 2, 2012, and accepted in revised form November 1, 2012.

Address correspondence to: Florian Lang, Physiologisches Institut der Universität Tübingen, Gmelinstr. 5, D-72076 Tübingen, Germany. Phone: 49.7071.29.72194; Fax: 49.7071.29.5618; E-mail: florian.lang@uni-tuebingen.de.
1. Foley RN, Parfrey PS, Sarnak MJ. Epidemiology of cardiovascular disease in chronic renal disease. J Am Soc Nephrol. 1998;9(12 suppl):S16-S23.

2. Blacher J, Guerin AP, Pannier B, Marchais SJ, London GM. Arterial calcifications, arterial stiffness, and cardiovascular risk in end-stage renal disease. Hypertension. 2001;38(4):938-942.

3. London GM, Guerin AP, Marchais SJ, Metivier F, Pannier B, Adda H. Arterial media calcification in end-stage renal disease: impact on all-cause and cardiovascular mortality. Nephrol Dial Transplant. 2003;18(9):1731-1740.

4. Moe SM, Drueke T, Lameire N, Eknoyan G. Chronic kidney disease-mineral-bone disorder: a new paradigm. Adv Chronic Kidney Dis. 2007; 14(1):3-12.

5. Mizobuchi M, Towler D, Slatopolsky E. Vascular calcification: the killer of patients with chronic kidney disease. J Am Soc Nephrol. 2009;20(7):1453-1464.

6. Hu MC, et al. Klotho deficiency causes vascular calcification in chronic kidney disease. J Am Soc Nephrol. 2011;22(1):124-136.

7. Kuro O. Phosphate and Klotho. Kidney Int Suppl. 2011;(121):S20-S23.

8. Kuro-o M, et al. Mutation of the mouse klotho gene leads to a syndrome resembling ageing. Nature. 1997;390(6655):45-51.

9. Yoshida T, Fujimori T, Nabeshima Y. Mediation of unusually high concentrations of 1,25-dihydroxyvitamin D in homozygous klotho mutant mice by increased expression of renal 1alpha-hydroxylase gene. Endocrinology. 2002;143(2):683-689.

10. Giachelli CM. Vascular calcification: in vitro evidence for the role of inorganic phosphate. J Am Soc Nephrol. 2003;14(9 suppl 4):S300-S304.

11. Tonelli M, Sacks F, Pfeffer M, Gao Z, Curhan G. Relation between serum phosphate level and cardiovascular event rate in people with coronary disease. Circulation. 2005;112(17):2627-2633.

12. Steitz SA, et al. Smooth muscle cell phenotypic transition associated with calcification: upregulation of $\mathrm{Cbfa} 1$ and downregulation of smooth muscle lineage markers. Circ Res. 2001; 89(12):1147-1154.

13. Jono $S$, et al. Phosphate regulation of vascular smooth muscle cell calcification. Circ Res. 2000; 87(7):E10-E17.

14. Nowik M, et al. Renal phosphaturia during metabolic acidosis revisited: molecular mechanisms for decreased renal phosphate reabsorption. Pflugers Arch. 2008;457(2):539-549.
15. Son BK, et al. Adiponectin antagonizes stimulatory effect of tumor necrosis factor-alpha on vascular smooth muscle cell calcification: regulation of growth arrest-specific gene 6-mediated survival pathway by adenosine 5 '-monophosphate-activated protein kinase. Endocrinology. 2008;149(4):1646-1653.

16. Lee HL, Woo KM, Ryoo HM, Baek JH. Tumor necrosis factor-alpha increases alkaline phosphatase expression in vascular smooth muscle cells via MSX2 induction. Biochem Biophys Res Commun. 2010;391(1):1087-1092.

17. Sun Y, et al. Smooth muscle cell-specific runx 2 deficiency inhibitsvascular calcification. Circ Res. 2012; 111(5):543-552.

18. Al Aly Z, et al. Aortic Msx2-Wnt calcification cascade is regulated by TNF-alpha-dependent signals in diabetic Ldlr $^{-/}$mice. Arterioscler Thromb Vasc Biol. 2007;27(12):2589-2596

19. Shao JS, Cheng SL, Pingsterhaus JM, Charlton-Kachigian N, Loewy AP, Towler DA. Msx2 promotes cardiovascular calcification by activating paracrine Wnt signals. J Clin Invest. 2005; 115(5):1210-1220.

20. Liu H, et al. Augmented Wnt signaling in a mammalian model of accelerated aging. Science. 2007; 317(5839):803-806.

21. Caverzasio J, Manen D. Essential role of Wnt3amediated activation of mitogen-activated protein kinase p38 for the stimulation of alkaline phosphatase activity and matrix mineralization in C3H10T1/2 mesenchymal cells. Endocrinology. 2007; 148(11):5323-5330.

22. Shroff RC, et al. Dialysis accelerates medial vascular calcification in part by triggering smooth muscle cell apoptosis. Circulation. 2008;118(17):1748-1757.

23. Maekawa Y, et al. Klotho suppresses TNF-alpha-induced expression of adhesion molecules in the endothelium and attenuates NF-kappaB activation. Endocrine. 2009;35(3):341-346.

24. Sanz-Rosa D, et al. Participation of aldosterone in the vascular inflammatory response of spontaneously hypertensive rats: role of the NFkappaB/ IkappaB system. J Hypertens. 2005;23(6):1167-1172.

25. Lim K, et al. Vascular Klotho deficiency potentiates the development of human artery calcification and mediates resistance to fibroblast growth factor 23 . Circulation. 2012;125(18):2243-2255

26. Takei Y, et al. Stanniocalcin 2 is associated with ectopic calcification in alpha-klotho mutant mice and inhibits hyperphosphatemia-induced calcification in aortic vascular smooth muscle cells. Bone.
2012;50(4):998-1005

27. Fischer SS, et al. Hyperaldosteronism in Klotho-deficient mice. Am J Physiol Renal Physiol. 2010; 299(5):F1171-F1177.

28. Hene RJ, Boer P, Koomans HA, Mees EJ. Plasma aldosterone concentrations in chronic renal disease. Kidney Int. 1982;21(1):98-101.

29. Brown NJ. Eplerenone: cardiovascular protection. Circulation. 2003;107(19):2512-2518.

30. Quaschning T, Ruschitzka F, Shaw S, Luscher TF. Aldosterone receptor antagonism normalizes vascular function in liquorice-induced hypertension. Hypertension. 2001;37(2 part 2):801-805.

31. de Jager DJ, et al. Cardiovascular and noncardiovascular mortality among patients starting dialysis. JAMA. 2009;302(16):1782-1789.

32. Kuro-o M. Klotho and the aging process. Korean J Intern Med. 2011;26(2):113-122.

33. Jaffe IZ, Mendelsohn ME. Angiotensin II and aldosterone regulate gene transcription via functional mineralocortocoid receptors in human coronary artery smooth muscle cells. Circ Res. 2005; 96(6):643-650.

34. Jaffe IZ, Tintut Y, Newfell BG, Demer LL, Mendelsohn ME. Mineralocorticoid receptor activation promotes vascular cell calcification. Arterioscler Thromb Vasc Biol. 2007;27(4):799-805.

35. Wu SY, et al. Endogenous aldosterone is involved in vascular calcification in rat. Exp Biol Med (Maywood). 2012;237(1):31-37.

36. Siragy HM, Xue C. Local renal aldosterone production induces inflammation and matrix formation in kidneys of diabetic rats. Exp Physiol. 2008; 93(7):817-824.

37. Li X, Yang HY, Giachelli CM. Role of the sodium-dependent phosphate cotransporter, Pit-1, in vascular smooth muscle cell calcification. Circ Res. 2006; 98(7):905-912.

38. Villa-Bellosta R, Bogaert YE, Levi M, Sorribas V. Characterization of phosphate transport in rat vascular smooth muscle cells: implications for vascular calcification. Arterioscler Thromb Vasc Biol. 2007; 27(5):1030-1036.

39. Villa-Bellosta R, Levi M, Sorribas V. Vascular smooth muscle cell calcification and SLC20 inorganic phosphate transporters: effects of PDGF, TNF-alpha, and Pi. Pflugers Arch. 2009;458(6):1151-1161.

40. McCurley A, Jaffe IZ. Mineralocorticoid receptors in vascular function and disease. Mol Cell Endocrinol. 2012;350(2):256-265.

41. Shin V, Zebboudj AF, Bostrom K. Endothelial cells 
modulate osteogenesis in calcifying vascular cells. J Vasc Res. 2004;41(2):193-201.

42. Kanno Y, Into T, Lowenstein CJ, Matsushita K. Nitric oxide regulates vascular calcification by interfering with TGF- signalling. Cardiovasc Res. 2008; 77(1):221-230

43. Takeshita K, et al. Increased expression of plasminogen activator inhibitor-1 with fibrin deposition in a murine model of aging, "Klotho" mouse. Semin Thromb Hemost. 2002;28(6):545-554.

44. Stubbs JR, et al. Role of hyperphosphatemia and 1,25-dihydroxyvitamin $\mathrm{D}$ in vascular calcification and mortality in fibroblastic growth factor 23 null mice. J Am Soc Nephrol. 2007;18(7):2116-2124.

45. Morishita K, et al. The progression of aging in klotho mutant mice can be modified by dietary phosphorus and zinc. J Nutr. 2001;131(12):3182-3188.

46. Tsujikawa H, Kurotaki Y, Fujimori T, Fukuda K, Nabeshima Y. Klotho, a gene related to a syndrome resembling human premature aging, functions in a negative regulatory circuit of vitamin $\mathrm{D}$ endocrine system. Mol Endocrinol. 2003;17(12):2393-2403.

47. Block GA, et al. Effects of phosphate binders in moderate CKD. J Am Soc Nephrol. 2012;23(8):1407-1415.

48. Aoshima Y, et al. Vitamin D receptor activators inhibit vascular smooth muscle cell mineralization induced by phosphate and TNF-alpha. Nephrol Dial Transplant. 2012;27(5):1800-1806.

49. Cohen-Lahav M, Shany S, Tobvin D, Chaimovitz C, Douvdevani A. Vitamin D decreases NFkappaB activity by increasing IkappaBalpha levels. Nephrol Dial Transplant. 2006;21(4):889-897.

50. $\mathrm{Al}$ Aly $\mathrm{Z}$. Vascular calcification in uremia: what is new and where are we going? Adv Chronic Kidney Dis. 2008;15(4):413-419.

51. Hamirani YS, et al. Markers of inflammation and coronary artery calcification: a systematic review. Atherosclerosis. 2008;201(1):1-7.

52. Sowers KM, Hayden MR. Calcific uremic arteriolopathy: pathophysiology, reactive oxygen species and therapeutic approaches. Oxid Med Cell Longev. 2010;3(2):109-121.

53. de Borst MH, Vervloet MG, ter Wee PM, Navis
G. Cross talk between the renin-angiotensin-aldosterone system and vitamin D-FGF-23-klotho in chronic kidney disease. J Am Soc Nephrol. 2011; 22(9):1603-1609.

54. Narumiya $\mathrm{H}$, et al. HMG-CoA reductase inhibitors up-regulate anti-aging klotho mRNA via RhoA inactivation in IMCD3 cells. Cardiovasc Res. 2004; 64(2):331-336

55. Rakugi $\mathrm{H}$, et al. Anti-oxidative effect of Klotho on endothelial cells through cAMP activation. Endocrine. 2007;31(1):82-87.

56. Slight SH, Joseph J, Ganjam VK, Weber KT Extra-adrenal mineralocorticoids and cardiovascular tissue. J Mol Cell Cardiol. 1999;31(6):1175-1184.

57. Tang C, Pathare G, Michael D, Fajol A, Eichenmuller M, Lang F. Downregulation of Klotho expression by dehydration. Am J Physiol Renal Physiol. 2011;301(4):F745-F750.

58. Dimitriadis G, Papadopoulos V, Mimidis K. Eplerenone reverses spironolactone-induced painful gynaecomastia in cirrhotics. Hepatol Int. 2011; 5(2):738-739.

59. Moghetti P, et al. Spironolactone, but not flutamide, administration prevents bone loss in hyperandrogenic women treated with gonadotropin-releasing hormone agonist. J Clin Endocrinol Metab. 1999; 84(4):1250-1254

60. McRobb L, Handelsman DJ, Heather AK. Androgen-induced progression of arterial calcification in apolipoprotein E-null mice is uncoupled from plaque growth and lipid levels. Endocrinology. 2009; 150(2):841-848.

61. Son BK, et al. Androgen receptor-dependent transactivation of growth arrest-specific gene 6 mediates inhibitory effects of testosterone on vascular calcification. J Biol Chem. 2010;285(10):7537-7544.

62. Haruna Y, et al. Amelioration of progressive renal injury by genetic manipulation of Klotho gene. Proc Natl Acad Sci U S A. 2007;104(7):2331-2336.

63. Kendrick J, Chonchol M. The role of phosphorus in the development and progression of vascular calcification. Am J Kidney Dis. 2011;58(5):826-834.

64. Koleganova N, et al. Arterial calcification in patients with chronic kidney disease. Nephrol Dial Transplant. 2009;24(8):2488-2496.

65. Edwards NC, Steeds RP, Chue CD, Stewart PM, Ferro CJ, Townend JN. The safety and tolerability of spironolactone in patients with mild to moderate chronic kidney disease. Br J Clin Pharmacol. 2012; 73(3):447-454.

66. Nakano-Kurimoto R, et al. Replicative senescence of vascular smooth muscle cells enhances the calcification through initiating the osteoblastic transition. Am J Physiol Heart Circ Physiol. 2009; 297(5):H1673-H1684.

67. Gui T, et al. MicroRNAs that target $\mathrm{Ca}(2+)$ transporters are involved in vascular smooth muscle cell calcification. Lab Invest. 2012;92(9):1250-1259.

68. Chiga M, et al. Dietary salt regulates the phosphorylation of OSR1/SPAK kinases and the sodium chloride cotransporter through aldosterone. Kidney Int. 2008;74(11):1403-1409.

69. Lippoldt A, Gross V, Bohlender J, Ganten U, Luft FC. Lifelong angiotensin-converting enzyme inhibition, pressure natriuresis, and renin-angiotensin system gene expression in transgenic (mRen-2)27 rats. J Am Soc Nephrol. 1996;7(10):2119-2129.

70. Axel DI, Brehm BR, Wolburg-Buchholz K, Betz EL, Koveker G, Karsch KR. Induction of cell-rich and lipid-rich plaques in a transfilter coculture system with human vascular cells. J Vasc Res. 1996; 33(4):327-339

71. Riessen R, Axel DI, Fenchel M, Herzog UU, Rossmann H, Karsch KR. Effect of HMG-CoA reductase inhibitors on extracellular matrix expression in human vascular smooth muscle cells. Basic Res Cardiol. 1999;94(5):322-332.

72. Voelk1 J, et al. Sgk1 sensitivity of $\mathrm{Na}(+) / \mathrm{H}(+)$ exchanger activity and cardiac remodeling following pressure overload. Basic Res Cardiol. 2012; 107(2):1-15.

73. Mossbrugger I, Hoelzlwimmer G, Calzada-Wack J, Quintanilla-Martinez L. Standardized morphological phenotyping of mouse models of human diseases within the German Mouse Clinic. Verh Dtsch Ges Pathol. 2007;91:98-103. 